\title{
TIPOGRAFI KREASI DARI MOTIF UKIR MELAYU DELI
}

\author{
Rinanda Purba \\ Prodi Desain Komunikasi Visual \\ Fakultas Seni dan Desain Universitas Potensi Utama \\ rinanda.purba.silangit@gmail.com
}

\begin{abstract}
Abstrak
Perancangan tipografi merupakan proses pembuatan huruf, angka, tanda baca yang mengadaptasi dari motif ukir yang dimiliki oleh masyarakat Melayu Deli di sumatera utara dengan mengikuti kaidah dan tata rancangan tipografi. Penelitian dilakukan di sudut-sudutruang Istana Maimunyang ada di Sumatera Utara. Multikulturalisme yang terjadi di sumatera utara terkhusus di kota Medan menimbulkan penurunan budaya masyarakat Melayu Deli, pewarisan budaya yang dapat dikatakan hampir berhenti karna budaya asing yang dianggap lebih menarik bagi generasi muda. Proses penggarapan ide yaitu dengan menggabungkan font yang sudah ada dengan motif ukir Pakis Melayu Deli yang sudah melalui tahapan stilasi sehingga menghasilkan sebuah bentuk baru yang mencerminkan identitas budaya Melayu Deli itu sendiri. Tujuan dari perancangan ini yaitu agar kearifan budaya lokal mampu tumbuh dan berkembang baik di kalangan generasi muda.
\end{abstract}

Kata kunci: Tipografi, Pakis, Melayu, Deli, Budaya

\begin{abstract}
Typography design is the process of making letters, numbers, punctuation that adapt from motif carving owned by Melayu Deli society in north sumatera by following rules and typography design. The study was conducted in the corners of the Maimun Palace in North Sumatra. Because of multiculturalism in North Sumatera in particular in the city of Medan caused a decline in the culture of the Batak community, a cultural heritage that can be said almost stopped because of foreign culture which is considered more attractive for the younger. The process of cultivating the idea is to combine the existing fonts with Pakis Melayu Deli carving motif that has been through Stages to produce a new form that reflects the identity of Melayu Deli culture itself. The purpose of this design is that the local cultural heritage is able to grow and develop well among the younger generation.
\end{abstract}

Keywords: Typhography, Pakis, Melayu, Deli, Culture

\section{PENDAHULUAN}

Kekayaan budaya yang ada di Sumatera sangat beragam dan unik. salah satu kebudayaan yang sudah sangat tua di sumatera utara ialah kebudayaan Melayu Deli. Melayu Deli tidak hanya terkenal melalui tari zapin yang sangat khas tetapi juga memiliki kekhasan dalam hal kesenian ukir yaitu pakis melayu.Pakis Melayu terdapat di bebrapa bagian bangunan/rumah adat Melayu Deli di bagian luardandalam bangunan untuk menghiasi melalui ornamen dengan paduan warna utama yaitu hijaudankuning.

Hampir di setiap rumah adat Melayu Delimemilikiukiran Pakis Melayu sebagai ragam hiasnya yang memberikan kesan estetis ketika memandangnya. Ukiran Pakis Melayu Deli memiliki ciri khas pada lekukan dari bentuk dasarnya berupa tumbuhan. Elemen estetis 
ini perkembangannya hanya pada ornamen rumah dan furniturepada ranah tradisi, sehingga popularitasnya sulit untuk masuk ke generasi remaja yang bergaya modern.

Eksistensi ornamen Pakis Melayu Deli sangat jarang ditemui dalam seni grafis modern. Gaya desain moderen barat menjadi tren bagi para desainer grafis menjadikan ornamen tradisi semakin tertinggal. Kondisi ini menginspirasi peneliti untuk merancang tipografi digital bercorak Pakis Melayu Deli yang menggabungkan konsep tradisi dan modern.

Tipografi merupakan salah satu unsur terpenting dalam karya seni grafis. Sebagai huruf, tipografi memiliki peranan sebagai elemen visual yang dapat dilihat (rupa huruf) dan elemen verbal yang dapat dibaca (tekstual). Selain itu, Pemaknaan terhadap tipografi kian berkembang seiring berkembangnya teknologi sehingga menurut Rustan (2011:16), tipografi dapat dimaknai sebagai segala disiplin ilmu yang berkenaan dengan huruf.

Pernancangan tipografi kreasi dari motif Pakis Melayu Deli secara klasifikasi huruf termasuk kedalam kelompok huruf display atau dekoratif. Penggunaan huruf dekoratif lebih difokuskan pada keindahannya dibandingkan legibilitasnya.

\section{STUDI LITERATUR}

Beberapa tulisan dan karya yang dijadikan rujukan dalam penelitian ini adalah tulisan Hery Ristiawan (2015) dalam makalahnya yang berjudul "Tipografi Digital Dari Corak Perisai Suku Dayak Kalimantan Barat". Makalah ini berisikan kajian tentang informatika sosial melihat aspek sosial dari komputerisasi yang menjadi studi interdisipliner dari perancangan, penggunaan, dan konsekuensi dari teknologi informasi yang memperhitungkan interaksi TI dengan konteks kultural. Perancangan tipografi digital ini merupakan proses pembuatan huruf dan angka yang mengambil motif dari corak perisai suku Dayak di Kalimantan Barat dengan teknik komputerisasi sesuai dengan kaidah tipografi, hingga tipografi ini bisa digunakan pada sistem operasi windows. Penelitian dilakukan pada masyarakat Adat Dayak di Binuo Garantunkg, Singkawang. Masalah yang terjadi pada komunitas adat ini adanya dekadensi atau kemunduran budaya pada masyarakat yang ditandai dengan adopsi budaya luar yang begitu cepat, sementara penyampaian proses inkulturisasi atau penyampaian ciri budaya dari satu generasi ke generasi berikutnya hampir berhenti dikarenakan budaya luar lebih menarik dan para penggiat seni dan budaya itu termakan usia. Perancangan menggunakan metode penelitian kualitatif, identifikasi persepsi visual secara sederhana dengan logika berpikir, jika acuan ditambah dengan kreasi akan membentuk hal yang baru, begitu pula dengan pengembangan tipografi ini, dari acuan huruf sans serif sebagai ditambah dengan corak perisai menjadikan alphabet dengan gaya tersendiri. Tujuannya adalah membuat sesuatu yang bernilai dari kearifan lokal, menunjukan identitas unik dari adopsi ilmu, budaya dan seni yang dapat diterapkan pada media-media komunikasi, serta dapat berjalan beriringan dengan kemajuan teknologi informasi sebagai bentuk nyata pelestarian budaya lokal.

Selanjutnya tulisan Ramalina Silaen (2015) dalam makalahnya yang berjudul "Perancangan Typeface Berbasis Aksara Batak Toba". Makalah ini menjelaskan tentang Aksara Batak Toba yang merupakan warisan budaya luhur suku Batak yang mendiami daerah Tapanuli. Dari lima jenis suku Batak yang ada masing-masing memiliki aksara sesuai tempat penggunaannya. Penggunaan aksara ini tidak lagi efektif pada masa kini karena huruf latin lebih dominan dan efisien digunakan dalam berkomunikasi. Dahulu kala aksara kebanyakan digunakan para datu sebagai pemimpin upacara adat namun seiring perkembangan waktu pengguna aksara tidak 
sebanyak dahulu. Aksara menjadi jarang digunakan dan mulai terlupakan karena sifat aplikatifnya yang terbatas di masa kini. Dengan demikian aksara ini membutuhkan perhatian khusus agar aksara ini tetap memiliki tempat dalam tatanan nilai budaya Batak Toba. Ide ini kemudian dikembangkan menjadi sebuah konsep rancang visual typeface berbasis aksara Batak Toba yang memiliki karakter anatomi dan proses konstruksi pembuatannya didasarkan pada kaidah-kaidah dalam tipografi, sehingga adaptasi ini muncul dalam rupa font latin. Dari bentuk aksara silabis (suku kata) menjadi fonetik (huruf tunggal) aplikasinya sebagai font di komputer. Setelah penelitian dan perancangan, kemudian typeface yang siap pakai ini disosialisasikan di area lokal, diprioritaskan pada tingkat pendidikan dan pemerintahan, yang pada penggunaannya untuk kepentingan headline.

Tulisan yang selanjutnya merupakan "Perancangan Tipografi Asimilasi Aksara Latin Karakteristik Ondel-Ondel Sebagai Solusi Kreatif Melestarikan Budaya Betawi” dalam penelitian yang dilakukan oleh Dhika Quarta Rosita yang berisikan tentang Masyarakat Betawi terus berkembang dari masa ke masa dengan ciri-ciri budaya yang makin lama semakin baik sehingga mudah dibedakan dengan kelompok etnis lain. Minimnya aktifitas pelestarian Ondel-ondel berbasis visual menjadi alasan perancangan tipografi asimilasi aksara latin karakteristik Ondel-ondel. Tujuannya adalah untuk pelestarian budaya Betawi khususnya Ondel-ondel melalui sebuah perancangan tipografi asimilasi aksara latin. Tipografi Ondel-ondel dimaksudkan sebagai upaya pelestarian kebudayaan Betawi dengan berbasis visual sesuai dengan berkembangnya teknologi saat ini. Metode penelitian yang digunakan adalah kualitatif dengan melakukan observasi untuk menganalisis bentuk tubuh Ondel-ondel guna mendapatkan karakteristik Ondel-ondel sebagai objek kajian yang dianalisis. Setelah kesimpulan didapat maka peneliti merancang tipografi asimilasi aksara latin karakteristik Ondel-ondel sebagai solusi kreatif melestarikan budaya Betawi. Teori yang akan digunakan dalam penelitian ini adalah teori dekontruksi (Derrida Jacques) dan ikonografi (Erwin Panofsky).

Perbedaan yang mendasar antara penelitian ini dengan tiga penelitian diatas adalah, pada penelitian yang dilakukan oleh Hery Ristiawan mengambil corak perisai suku Dayak sebagai sumber ide, kemudian penelitian yang dilakukan oleh Ramalina Silaen mengambil sumber ide dari bentuk aksara batak yang diterapkan kedalam font latin, selanjutnya penelitian yang dilakukan oleh Dhika Quarta Rosita menjadikan karakteristik Ondel-ondel sebagai sumber ide perancangan fontnya, sedangkan dalam penelitian ini penulis menjadikan motif ukir melayu deli sebagai sumber ide gagasan dalam perancangan font digital.

\section{PEMBAHASAN}

\section{III.1. Typography}

Typography adalah suatu ilmu dalam memilih dan menata huruf dengan pengetahuan penyebarannya pada ruang-ruang yang tersedia, untuk menciptakan kesan tertentu semaksimal mungkin. Dengan tujuan kenyamanan semaksimal mungkin pada saat membacanya baik dalam jarak dekat maupun jarak jauh sehingga maksud dan arti dari tulisan dapat tersampaikan dengan sangat baik secara visual kepada pembaca.

Pengertian Tipografi menurut Roy Brewer (1971) Pengertian Tipografi sendiri memiliki pengertian sangat luas yang mencakup penyusunan dan bentuk halaman, atau 
setiap barang cetak, tipografi dapat juga diartikan pemilihan, penataan dan berbagai hal yang berhubungan dengan pengaturan baris-baris serta susunan huruf (typeset), tidak termasuk didalamnya bentuk ilustrasi dan unsur-unsur lain yang bukan susunan huruf pada halaman cetak.

Tehnik Tipografi tidak terbatas pada pemilihan jenis huruf saja, ukuran huruf, bentuk huruf ataupun kecocokan dengan tema. Tetapi meliputi juga pengaturan tata letak vertikal/horizontal pada area desain. Tehnik Tipografi telah digunakan diberbagai bidang seperti desain web, desain grafis, desain produk, majalah, undangan, percetakan, dll.

Sejarah Tipografi dimulai dari penggunaan pictograph. Bentuk bahasa ini digunakan bangsa Indian Sioux dan Viking dari Norwegia. Kemudian di Mesir dikenal jenis huruf Hieratia yang dikenal dengan nama Hieroglif pada abad 1300 SM. Bentuk Tipografi merupakan akar dari bentuk Demotia, yang ditulis dengan pena khusus. Tehnik Tipografi terus berkembang hingga di Kreta, hingga Yunani dan keseluruh Eropa. Puncak perkembangan tipografi terjadi pada abad 8 SM di Roma, ketika itu pemerintahan Romawi mulai membentuk kekuasannya. Dikarenakan bangsa Romawi tidak mempunyai tulisan sendiri maka mereka mulai mempelajari tehnik penulisan masyarakat Italia yaitu Etruska dan kemudian menyempurnakannya sehingga terbentuklah jenis tulisan / huruf Romawi.

Perkembangan tipografi saat ini telah disentuh oleh perkembangan komputerisasi, sehingga dalam tehnik pembuatan tipografi menjadi lebih mudah dan lebih singkat penyelesaiannya dengan penggunaan jenis huruf yang berjumlah ratusan atau lebih. Terkadang secara tidak sadar, kita sering berhubungan dengan tipografi hampir setiap saat. Seperti koran atau majalah yang sering kita baca, label pakaian yang biasa kita gunakan dan masih banyak lagi contoh-contoh lainnya.

Dalam merancang tipografi, ada beberapa hal yang harus menjadi acuan. Salah satu acuan yang menjadi perhatian adalah anatomi huruf. Seperti halnya manusia, huruf juga memiliki anatomi dan struktur pembangun huruf itu sendiri sehingga gabungan antar struktur huruf yang satu dan yang lainnya dapat menjadi pembeda antar huruf satu dengan yang lain.

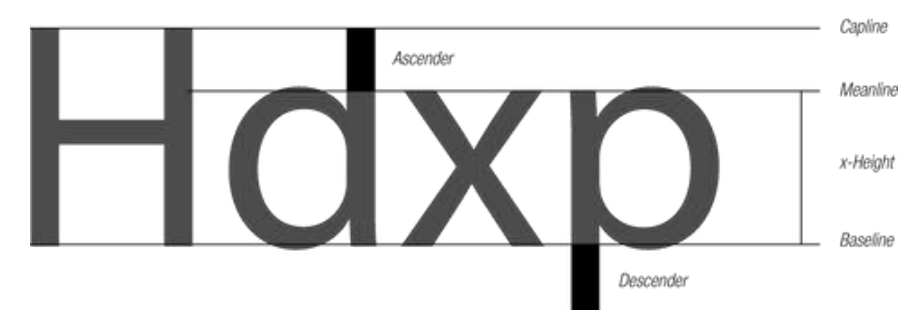

Gambar 1. Anatomi Huruf

Menurut Danton (2016: 128), terminologi yang umum digunakan dalam penamaan anatomi huruf diantaranya baseline, capheight, $x$-height, meanline, ascender, dan descender.

\section{Baseline}

Garis maya horisontal yang menempatkan huruf-huruf dalam posisi sejajar. Garis maya ini merupakan batas dari bagian terbawah huruf besar dan badan huruf kecil (tanpa ascender dan descender).

\section{Cap height}

Garis maya horisontal yang menjadi batas dari bagian teratas huruf besar. Desain huruf umumnya memiliki tinggi ascender sedikit diatas cap height, oleh karenanya terdapat terminologi ascender height yang menjadi garis batas ascender. 


\section{Meanline}

Garis maya horisontal yang menjadi batas dari bagian teratas dari badan huruf kecil.

\section{X-Height}

Tinggi dari badan huruf kecil, tanpa ascender dan descender. X-height dimulai dari baseline hingga meanline. Cara yang termudah melihat ketinggian badan huruf kecil adalah dengan menggunakan huruf kecil ' $x$ '.

\section{Ascender}

Bagian dari anatomi huruf kecil yang mengarah ke atas dan posisinya berada di atas meanline.

\section{Descender}

Bagian dari anatomi huruf kecil yang mengarah ke bawah dan posisinya berada di bawah baseline.

Ditinjau dari sudut geometri, maka garis dasar yang mendominasi struktur huruf dalam alfabet dapat di bagi menjadi 4 kelompok besar12, kelompok garis tegakdatar E F $\mathrm{H}$ I L, Kelompok garis tegakmiring A K M N V Z X Y W, kelompok garis tegak-lengkung B D G J P R U dan kelompok garis lengkung C O Q S. Dalam tipografi proporsi huruf dan kemiringan menjadi bagian penting Perbandingan antara tinggi huruf yang tercetak dengan lebar dari huruf itu sendiri dapat menjadi tiga kelompok bila ditinjau dari perbandingan proporsi terhadap bentuk dasar huruf tersebut. Pembagiannya adalah condensed, reguler, dan extended. Menurut danton (2001), huruf yang berjenis condensed dan extended lebih cenderung melelahkan mata dibanding dengan jenis regular, sehingga lebih tepat digunakan untuk judul dan sub judul.
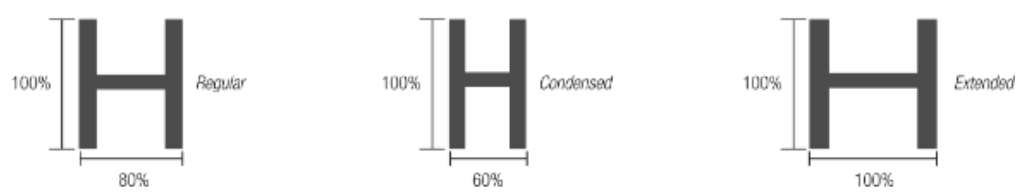

\section{Gambar 2. Proporsi Huruf}

\section{III.2. Motif Ukir Melayu Deli}

Menurut Sukarman (1982:3), ornamen dibuat untuk tujuan menghias suatu benda/barang dengan tujuan benda/barang yang dihias itu mempunyai nilai tambah dan mengakibatkan pula nilai tambah dalam segi finansial dan spiritual.

Ukiran merupakan hasil seni tradisi Melayu Deli yang diajarkan secara turun temurun. Sejarah seni ukir di Tanah Melayu banyak terdapat dalam catatan-catatan sejarah yaitu dalam sejarah Melayu sejak 500 tahun yang lalu. Orang-orang Melayu pada masa itu sudah memberi perhatian yang istimewa terhadap seni ukiran pada bangunan seperti istana dan kediaman. Tidak hanya masyarakat saja, Raja-raja pada zaman dahulu juga berperan penting dalam memperkembangkan dan menghidupkan suasana seni ukir. Hingga kini 
peninggalan istana-istana lama memperlihatkan betapa indah dan uniknya ukiran-ukiran yang diterapkan pada istana-istana tersebut. Berikut ragam ukiran yang ada di Istana Sultan Deli yaitu Istana maimun yang berada di Kota Medan.

Tabel 1. Ukiran Pakis Melayu

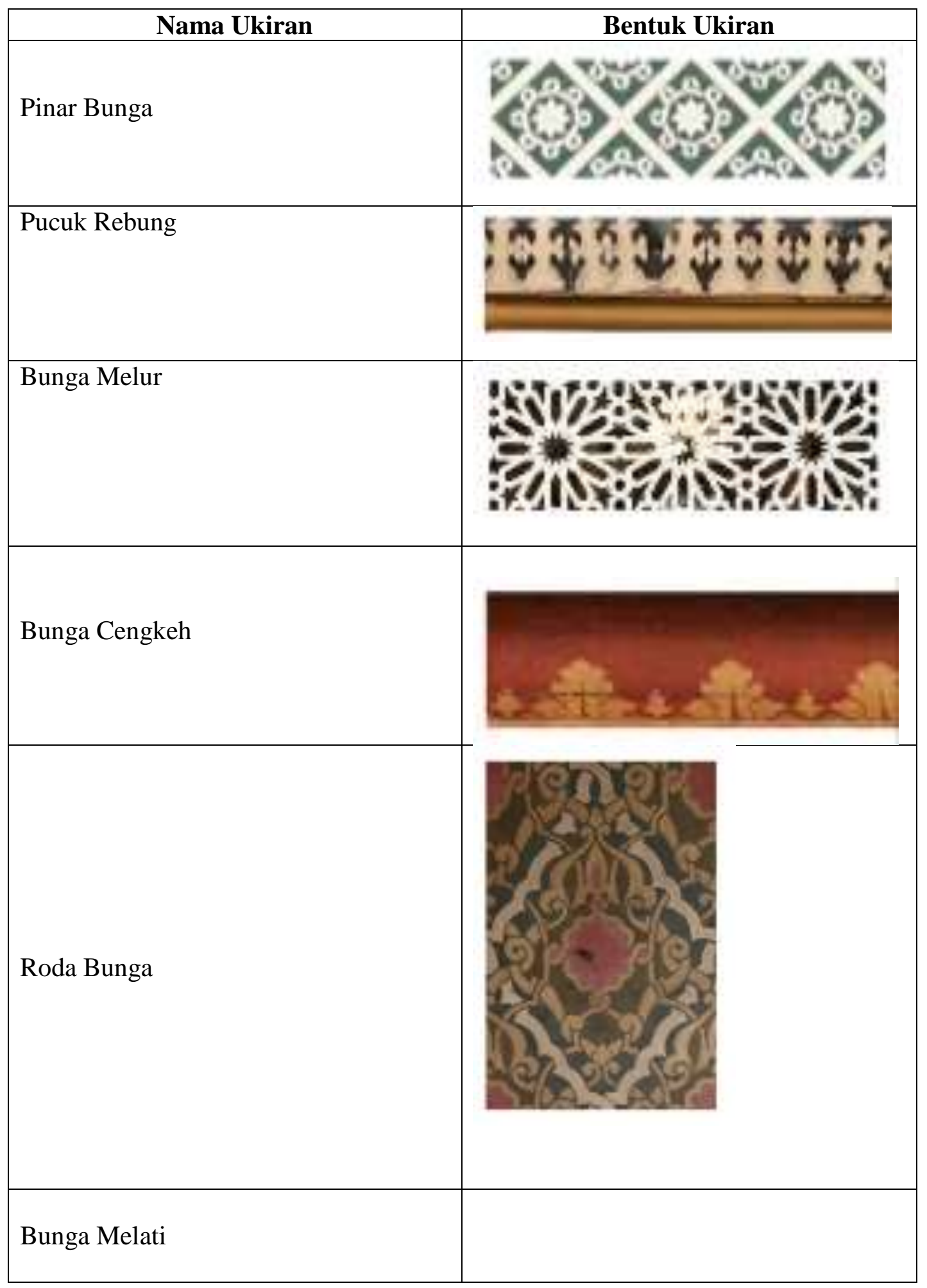




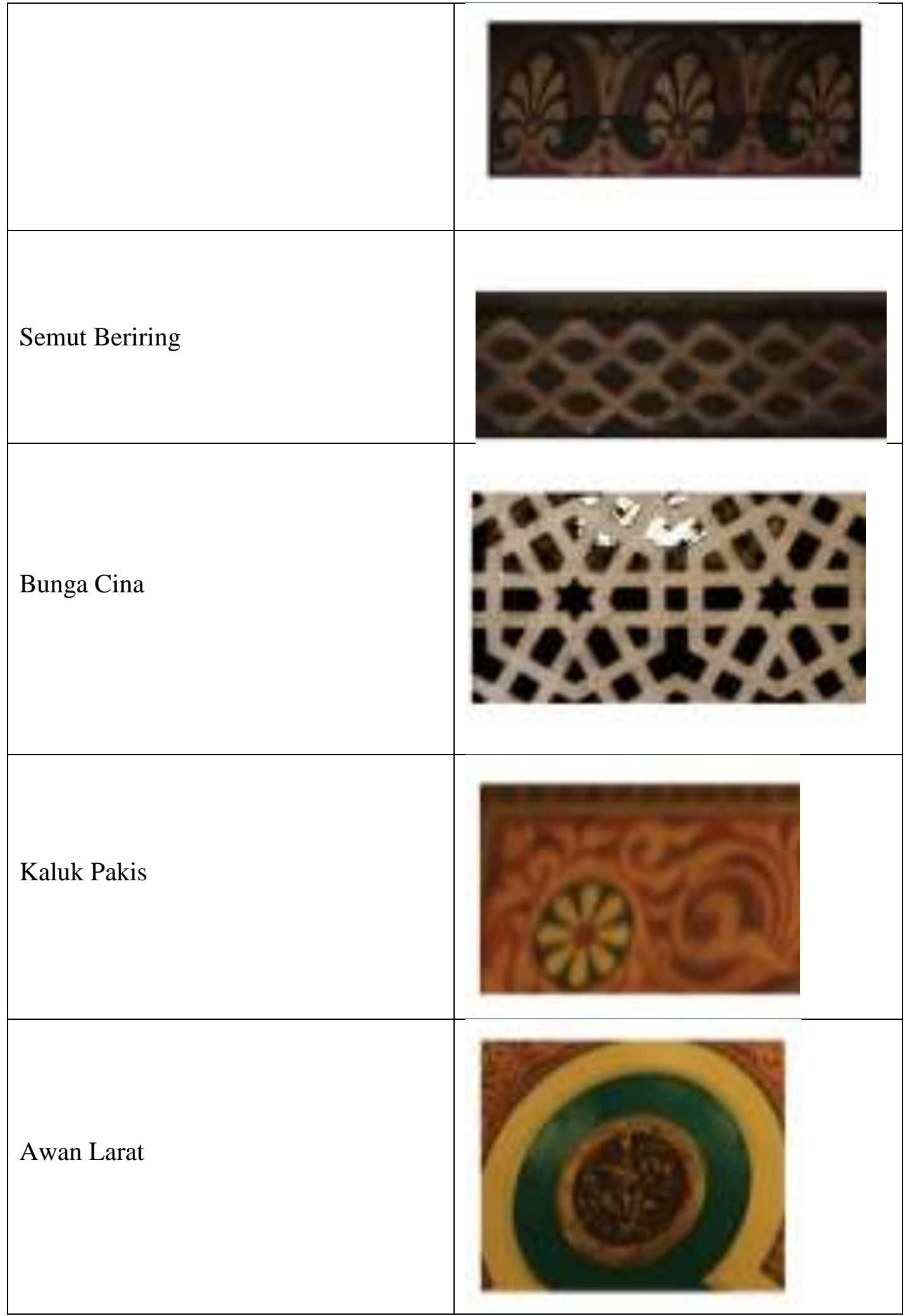




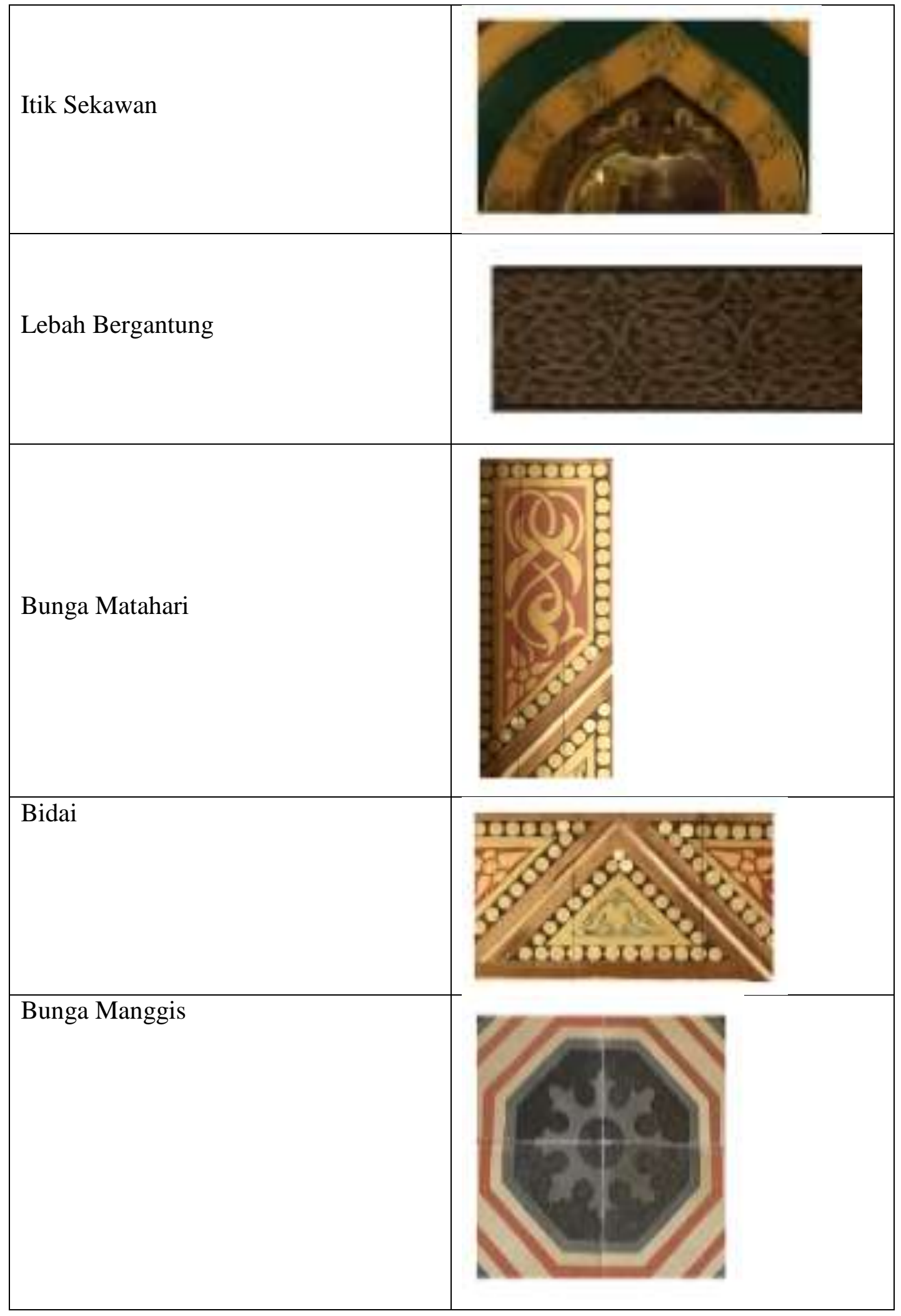

\section{III.3. Penjaringan Ide dan Konsep}

Pemahaman tentang anatomi huruf dasar yang digunakan sangatlah penting sebelum dilakukannya proses penggabungan atau penambahan ornamen pakis melayu deli yang khas. Dalam perancangan tipografi, haruslah memperhatikan konsep awal desain serta 
memperhatikan prinsip-prinsip dalam tipografi. Ada empat buah prinsip pokok tipografi yang sangat mempengaruhi keberhasilan suatu desain yaitu legability, clarity, visibility, danreadibility.

Legability adalah kualitas pada huruf yang membuat huruf tersebut dapat terbaca. Dalam sebuahkarya desain, dapat terjadi cropping, overlapping, dan lain sebagainya yang dapat menyebabkan berkurangnya legabilitas dari sebuah huruf. Untuk menghindari hal ini, maka seorang desainer harus mengenal dan mengerti karakter dari sebuah huruf dengan baik.

Readibility adalah penggunaan huruf dengan memperhatikan hubungannya dengan huruf yang lain sehingga terlihat jelas. Kerapatan dan kerenggangan teks dalam suatu desain juga dapat mempengaruhi keseimbangan desain. Teks yang spasinya sangat rapat akan terasa menguasai bidang kosing dalam suatu bentuk, sedang kanteks yang berjarak sangat jauh akan terasa lebih seperti tekstur.

Visibility merupakan kemampuan suatu huruf, kata, atau kalimat dalam sebuah karya desain dapat terbaca dalam jarak baca tertentu. Jarak baca dan ukuran huruf sangat berpengaruh dalam hal visibility sebuah huruf. Huruf-huruf yang digunakan dalam desain harus dapat terbaca dalam jarak tersebut sehingga suatu karya desain dapat berkomunikasi dengan baik.

Clarity merupakan kemampuan huruf yang digunakan dalam suatu karya desain dapat dibaca dan dimengerti oleh target audience yang dituju. Untuk suatu karya desain dapat berkomunikasi dengan audience, maka informasi yang disampaikan harus dapat dimengerti oleh audience yang dituju. Beberapa unsur desain yang dapat mempengaruhi clarity adalah urutan, warna, dan pemilihan type.

Dari keempat prinsip pokok tipografi tersebut, font baru bermotif gorga ini juga harus memenuhi legability, readibility, visibility, dan clarity sehingga ketika diimplementasikan ke berbagai media tidak terjadi masalah.

\section{a.Basic Idea}

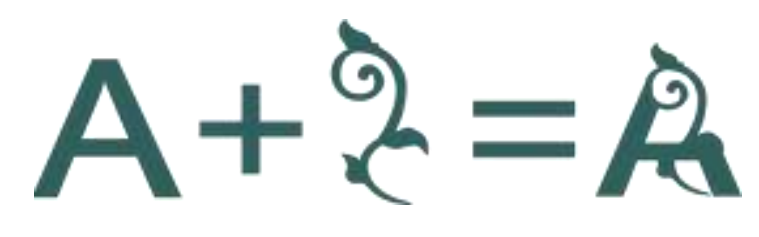

Gambar 3. Basic Idea

Ide dasar dalam perancangan tipografi kreasi ini yaitu dengan menggabungkan font dasar arial dengan motif pakis Melayu Deli. Penambahan ornament pada font dasar arial yang bersifat tegas tentu akan mempengaruhi struktur dari huruf dasar itus endiri. Berubahnya struktur dasar pada satu huruf akan sangat berpengaruh pada jarak anta rhuruf yang lain (kerning, leading, danspace). 


\section{b.Grid System}

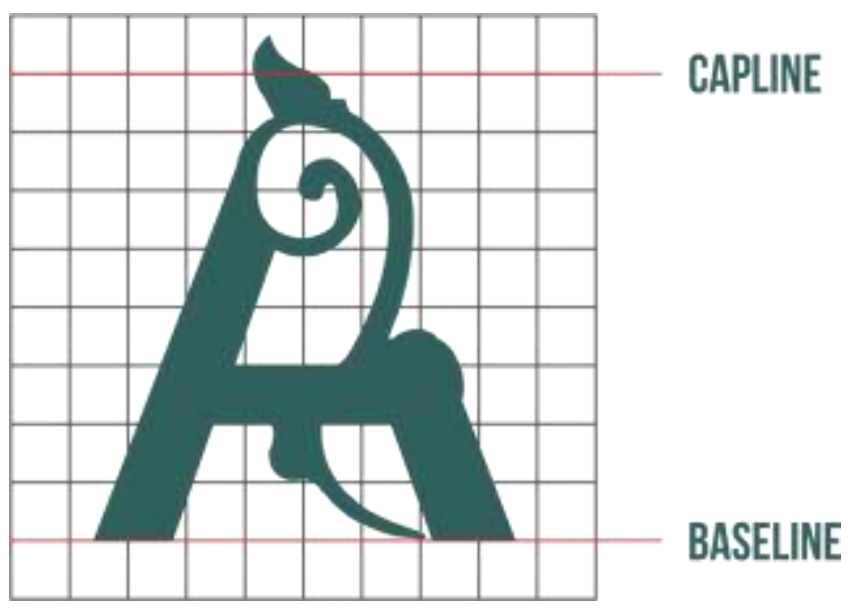

Gambar 4. Grid System

Huruf A pada grid di atas menempati batas atas dan bawah huruf yang diatur pada baseline yang merupakan batas bagian bawah huruf dan capline yang menjadi batas atas horizontal setiap huruf kapital.

Grid juga berfungsi untuk menentukan jarak antara huruf sebelum dan sesudahnya agar tidak bertumpuk pada ornamen yang dikreasikan. Jarak antar huruf ini disebut kerning.

Secara lengkap, anatomi huruf kreasi dari motif ukir Pakis Melayu Deli dapat dilihat pada gambar 20. Setiap huruf kecil masih menempati ruang setinggi X-height dan ornamen pada huruf kecil masuk ke ascender dan descender.

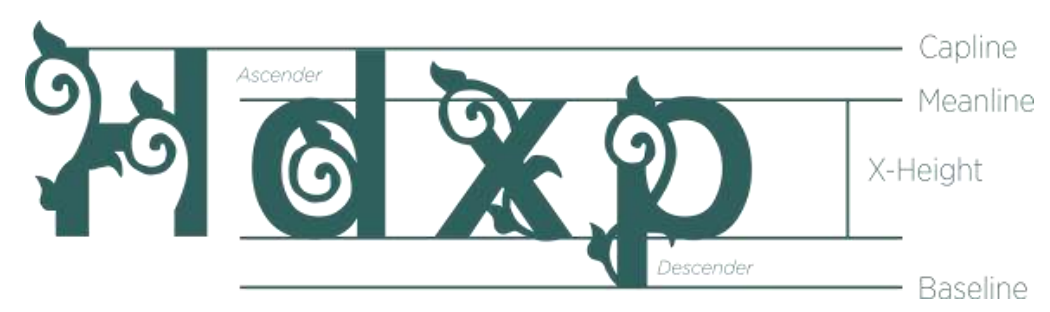

Gambar 5. Anatomi Huruf

\section{c. Figure dan Ground}

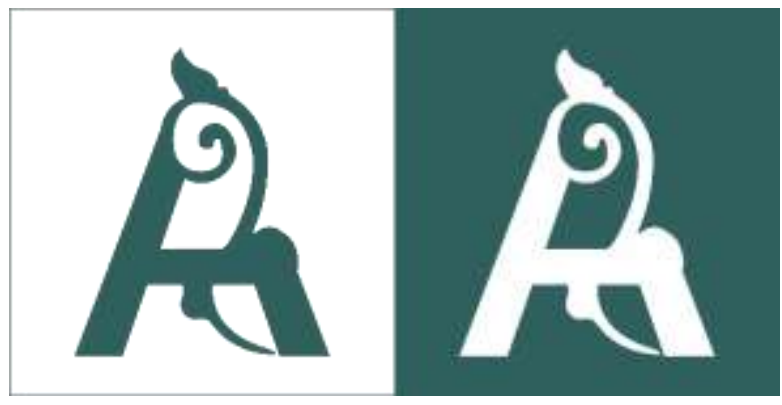

Gambar 6. Figure dan Ground 
Studi Figure dan Ground dibutuhkan agar ketika warna huruf di inverse dengan warna background, kejelasan huruf masih dapat terlihat dengan jelas.

\section{d. Final Uppercase}

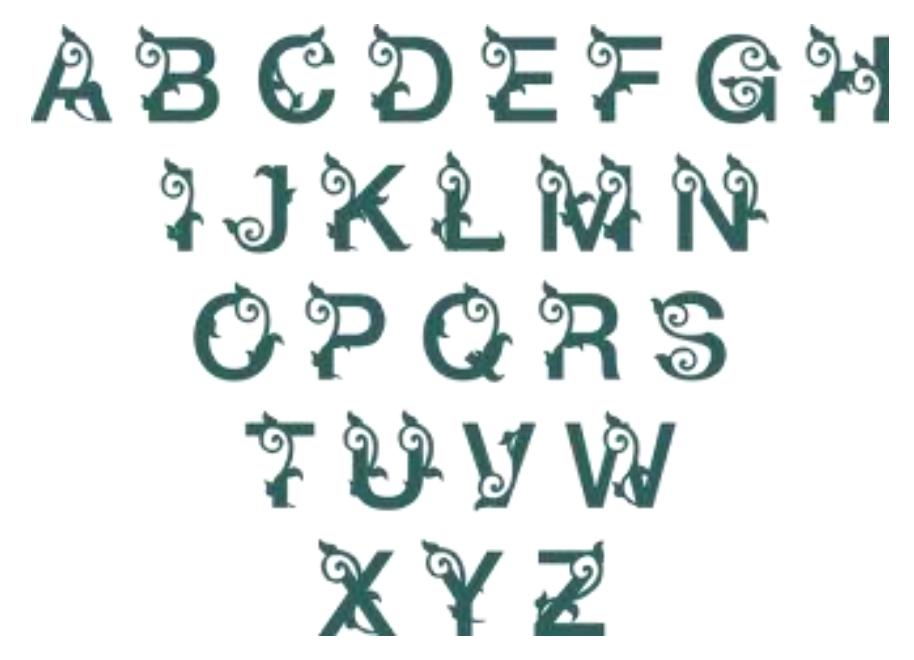

Gambar 7. Final Font Uppercase

Proses pembuatan font digital dilakukan menggunakan software CorelDraw untuk setiap karakter huruf yang kemudian diekspor kedalam bentuk file True Type Font (ttf).

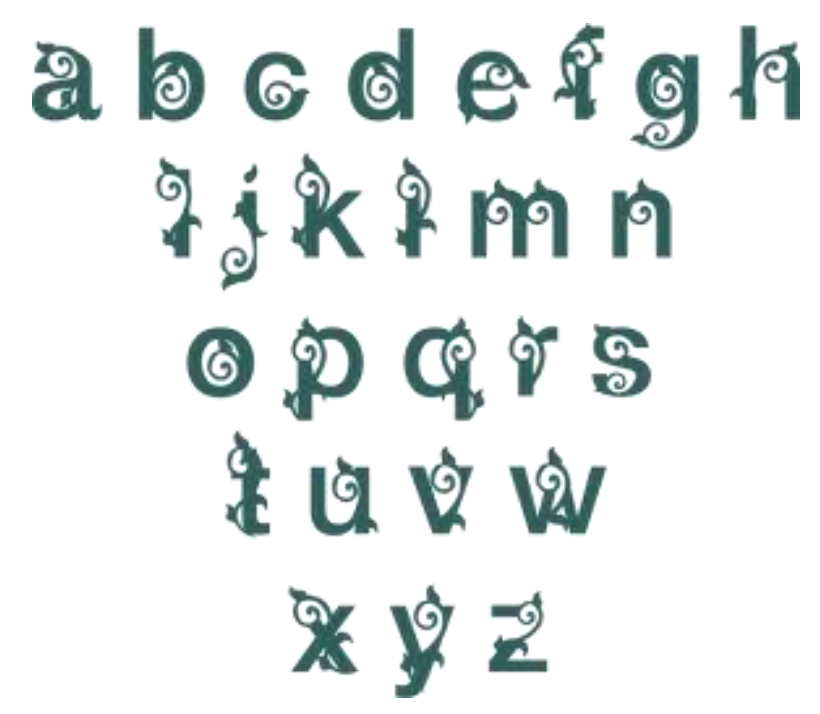

Gambar 8. Final Font Lowercase

\section{III.3. Data Pembanding}

Untuk menjaga orisinalitas karya, penelitian ini membandingkan beberapa karya tipografi yang sudah ada sebelumnya yang memiliki konsep sama yaitu budaya. Karya-karya tersebut diantaranya huruf Minangkabau dan tipografi Motif Dayak. Kedua font tersebut memiliki kekuatan yang sangat kuat dari sisi budaya lokalnya dan digarap dengan baik. 
a. Tipografi Kreasi Minangkabau

\section{ABEUEFEHIJKUM NOPQRSTUVWXYZ aljudefolojklm nopursturwxyz O1Z345678917 \#}

Gambar 9. Tipografi Kreasi Minangkabau

Kesan rumah gadang pada tipografi ini begitu kuat secara visual dan terkesan kokoh dengan pemilihan jenis huruf yang memiliki proporsi extend.

\section{b. Tipografi Kreasi Motif Dayak}

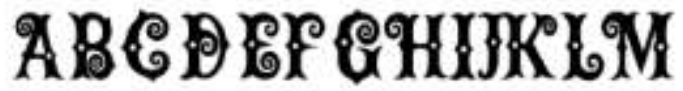

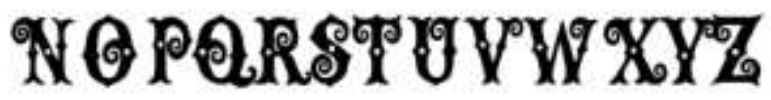 abcdefghijkım nopqrsturwxyz 1234567890}

Gambar 10. Tipografi Kreasi Motif Dayak

Konsep yang diusung oleh tipografi ini yaitu corak yang ada pada perisai suku Dayak di Kalimantan.Berangkat dari basic font cambria bold berjenis sans serif yang memiliki ketebalan sekaligus sudut yang tegas sehingga sesuai untuk memunculkan kesan gagah sekaligus artistik sebagaimana filosofi dari perisai sebagai senjata khas Kalimantan Barat. 


\section{KESIMPULAN}

Pelestarian budaya Melayu Deli dengan menggunakan cara publikasi dan promosi budaya saja tidaklah cukup. Seiring perkembangan zaman dan faktor masuknya budaya asing yang cenderung digemari oleh generasi muda akan membawa budaya Melayu semakin dilupakan. Oleh karena itu, harus dilakukan pendekatan modern dan penggunaan teknologi yang kian maju dalam penyampaian dan pelestarian budaya Melayu Deli.

Karyatipografi kreasi dari motif ukir Pakis Melayu Deli ini merupakan upaya dalam mempopulerkan budaya (tradisi) keranah seni grafis modern sehingga penggunaan ornamenornamen yang berbau tradisi dapat digunakan secara luas sebagai konsep desain para desainer masa kini.

Adanya karya ini diaharapkan agar dapat memicu desainer-desainer lain untuk turut serta dalam mengusung konsep tradisi. Menjadikan kearifan lokal sebagai sumber ide dalam setiap karya, baik karya tipografi maupun karya desain grafis lain.

\section{DAFTAR PUSAKA}

[1] Sihombing, D. 2001. Tipografi Dalam Desain Grafis. Jakarta : PT Gramedia Pustaka Utama.

[2] Sihombing, D. 2015. Tipografi Dalam Desain Grafis Edisi ke-2. Jakarta : PT Gramedia Pustaka Utama.

[3] Ristiawan, Hery. 2015. Tipografi Digital Dari Corak Perisai Suku Dayak Kalimantan Barat. Jurnal Teknologi Informasi Dan Komunikasi Ugm.

[4] Silaen, Ramalina. 2015. Perancangan Typeface Berbasis Aksara Batak Toba. EProceeding of Art and Design Telkom University.

[5] Rosita, Dhika. 2014. Perancangan Tipografi Asimilasi Aksara Latin Karakteristik Ondel-Ondel Sebagai Solusi Kreatif Melestarikan Budaya Betawi. Jurnal Desain Universitas Indraprasta PGRI Jakarta.

[6] Rustan, Surianto. 2011. Font dan Tipografi. Jakarta: PT. Gramedia Pustaka Utama.

[7] Brewer, Roy. 1971.The Man Who Loved Letters. Littlehampton Book Services.

[8] Sukarman. 2982. Pengantar Ornamen Timur I. Yogyakarta: STSRI. 